\title{
AIR MANCUR OTOMATIS DENGAN MUSIK BERBASIS ARDUINO
}

\author{
Silvia Ratna \\ Fakultas Teknologi Informasi, Universitas Islam Kalimantan Muhammad Arsyad Al Banjari Banjarmasin \\ via.borneo@gmail.com
}

\begin{abstract}
Fountains are widely used in parks as garden decorations. Many methods have been carried out such as the emission of fountains is not varied so the garden decoration in a long time is less attractive. In this study, the fountain setting can be varied by using the rhythm of the music played through android application by connecting her with bluetooth and song files placed on the module DF player. Stages carried out: input music sources, Arduino Uno, DF player mini, bluetooth, 31C TIP transistors, water pumps, water sources and android applications. By varying the rhythm of the music then varying the input voltage of the system by controlling using Arduino Uno, the system is able to adjust the work of the transistor so that the water pump can be adjusted, finally the rhythm of the music can adjust the output of water varies like a fountain.
\end{abstract}

Keywords: fountain, df player, music, water pumps

\begin{abstract}
Abstrak
Air mancur banyak digunakan di taman-taman sebagai hiasan taman. Banyak metode yang sudah dilakukan misalnya pancaran air mancur tidak bervariasi sehingga hiasan taman dalam waktu yang lama kurang menarik. Pada penelitian ini pengaturan air mancur yang dapat bervariasi dengan menggunakan irama musik yang diputar melalui aplikasi android dengan cara menghubungkan nya dengan bluetooth dan file lagu diletakan pada modul DF player. Tahapan-tahapan yang dilakukan: masukan sumber musik, Arduino Uno, DF player mini, bluetooth, Transistor TIP 31C, Pompa Air, Sumber Air dan aplikasi android. Dengan bervariasi irama musik maka bervariasi tegangan masukan kesistem dengan pengontrolan menggunakan arduino uno maka sistem mampu mengatur kerja Transistor sehingga pompa air dapat diatur, akhirnya irama musik dapat mengatur keluaran air bervariasi menyerupai air mancur.
\end{abstract}

Kata kunci: air mancur, df player, musik, pompa air

\section{PENDAhUluan}

Air mancur bagian dari sebuah taman yang sangat menarik dan dapat membuat suasana taman menjadi lebih indah dan lebih segar untuk dipandang. Akan tetapi biasanya pola dari air mancur yang tidak bervariasi, hal ini dapat membuat seseorang menjadi bosan apabila memperhatikan pola dari air mancur dalam jangka waktu tertentu. Untuk membuat sebuah air mancur taman membutuhkan biaya yang mahal. Oleh karena itulah maka dalam makalah dibuat suatu alat pengontrol bentuk semburan pada air mancur, dengan pola semburan air yang mengikuti irama musik yang Jurnal Ilmiah "Technologia" bervariasi sehingga lebih atraktif dan menarik serta sewaktu-waktu dapat diubah dengan mengganti musik yang diinginkan. Alat ini dibuat dengan kontrol arduino untuk mengendalikan air mancur yang akan dihasilkan. Air mancur ini merupakan alat kontrol yang digunakan untuk mengatur semburan air mancur sehingga air yang ke luar bukan hanya semburan yang kontinyu, tetapi dapat membuat semburan yang tinggi dan rendahnya semburan dapat diatur sesuai dengan PWM pada setiap motor. Air mancur megikuti irama musik yang terdapat pada modul mp3, untuk memutar file mp3 menggunakan pemutar 
musik yang dibuat dengan aplikasi android yang terhubung melalui bluetooth.

\section{METODOLOGI PENELITIAN}

Penelitian ini dilakukan berdasarkan tahapantahapan penting yang dikerjakan dengan berorientasikan kepada indikator keberhasilan dalam mengubungkan arduino dengan bluetooth untuk mengontrol air mancur sehingga dapat digunakan untuk menyelesaikan permasalahan multi objektif. Untuk dapat mencapai, indikator tersebut, maka tahapantahapan penelitian ini adalah sebagai berikut :

1. Analisa masalah, dalam hal ini kebutuhan menganalisa permasalahan yang akan diteliti mengenai air mancur otomatis .

2. Analisa kebutuhan, dalam hal ini segala kebutuhan dalam meneliti baik dari jurnal, buku, literatur-literatur, alat dan bahan.

3. Merancang alat yang akan dibangun dengan menggunakan arduino, bluetooh, modul df player dan pompa air submersible.

4. Melakukan pengujian air mancur

\subsection{Alat dan Bahan}

a. Perangkat Keras

1. Arduino Uno

Arduino uno sebagai sumber

penggontrol perangkas keras yang open

source, biasanya digunakan dalam

berbagai aplikasi yang memerlukan

performance tinggi dan mudah

diterapkan.

Model papan Mikrokontroler Arduino uno adalah ATmega328 yang spesifikasinya berisi 14 pin input / output digital (6 pin dapat digunakan sebagai output PWM), input analog 6 pin, Memori 32k Flash, koneksi USB, colokan daya dan tombol reset. Juga mudah untuk terhubung ke komputer dengan kabel USB untuk melakukan proses kompiler sehingga untuk menjalankannya untuk mengoperasikan perangkat keras itu

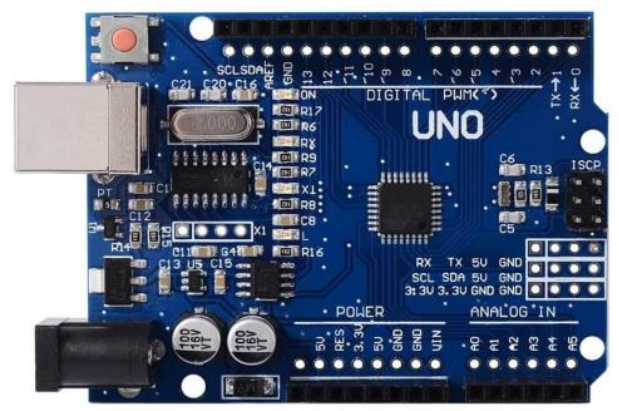

Gambar 2.1 Board Arduino Uno

2. Modul Bluetooh HC-05

Bluetooth Module HC-05 adalah sebuah module yang dapat dua mode slave atau master dengan frekuensi komunikasi $2.4 \mathrm{GHz}$. Modul ini mempunyai jarak efektif jangkauan 10 meter. Modul ini juga mudah untuk digunakan untuk membangun sistem wireless.

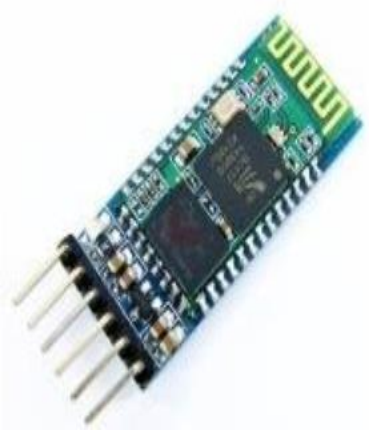

Gambar 2.2 Modul bluetooth HC-05

3. Modul DF player

Modul DFPLayer Mini adalah sebuah modul MP3 serial yang menyiakan kesempurnaan integrasi MP3, WMV hardware decoding. Sedangkan softwarenya mendukung driver TF card, mendukung sistem file FAT16, FAT32. Melalui perintah-perintah serial sederhana untuk menentukan memutar musik, serta bagaimana cara memutar musik dan fungsi lainnya, tidak melalui operasi yang rumit, mudah digunakan, stabil dan dapat diandalkan adalah fitur-fitur yang paling penting dari modul ini. Modul ini dapat digunakan sebagai modul yang berdiri sendiri dengan menggunakan baterai. 


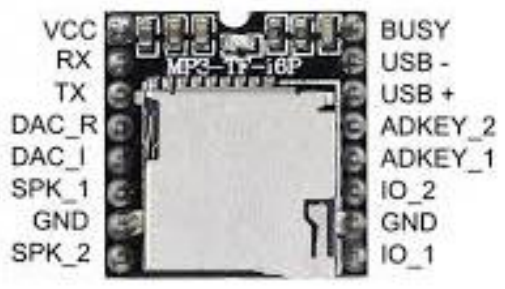

Gambar 2.3 Modul DF Player

4. Transistor TIP 31C

Transistor adalah komponen aktif semikonduktor yang berfungsi sebagai penguat arus dan sebagainya saklar. Transistor bipolar adalah komponen yang bekerja berdasarkan ada-tidaknya arus pemicuan pada kaki Basisnya. Pada aplikasi driver relay, transistor bekerja sebagai saklar yang pada saat tidak menerima arus pemicuan, maka transistor akan berada pada posisi cutoff dan tidak menghantarkan arus. TIP31C adalah transistor bipolar NPN standar dalam paket TO-220 dan sangat cocok untuk aplikasi switching daya menengah. TIP31C spesifik ini dapat menangani arus puncak $3 \mathrm{~A}$ dan dapat mengalihkan tegangan hingga $100 \mathrm{~V}$ DC.

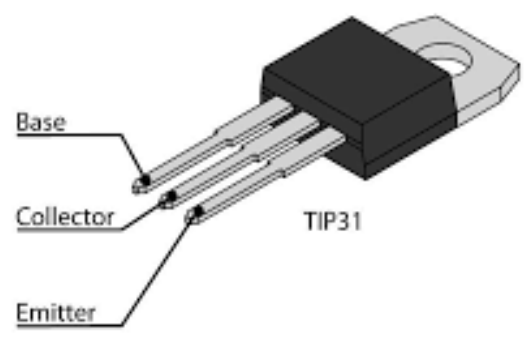

Gambar 2.4 Transistor NPN TIP 31C

5. Pompa air celup submersible Sesuai namanya, pompa air listrik ini penggunaannya dicelupkan ke dalam air. Pompa jenis ini bertipe pompa sentrifugal. Pompa sentrifugal sendiri prinsip kerjanya mengubah energi kinetis (kecepatan) cairan menjadi energi potensial (dinamis) melalui suatu impeller yang berputar dalam casing. Cara kerjanya pun sama seperti pompa air listrik yaitu memanfaatkan dayacentrifugal dari perputaran kipas impeller untuk mendorong air ke atas. Jenispompa air celup ini cukup banyak tergantung keperluannya

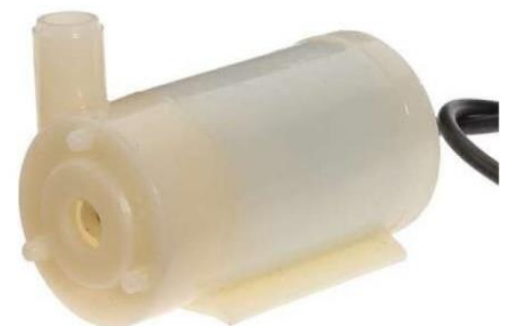

Gambar 2.5 Pompa air celup submersible

6. Adaptor 5V 5A

Pompa air celup submersible bekerja dengan catu daya 3-6v dan arus sebesar $220 \mathrm{~mA}$. Karena pada proyek air mancur ini memakai 5 (lima) buah pompa air, maka total arus yang diperlukan adalah 5A. Untuk menghasilkan semburan yang kuat di perlukan arus catu daya yang besar.

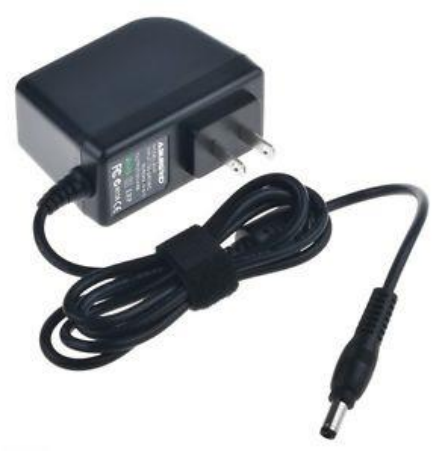

Gambar 2.6 Adaptor 5V

b. Software yang digunakan untuk pembuatan sistem:

1. Arduino IDE 1.8.7 digunakan untuk membuat code program

2. App Inventor digunakan untuk membuat aplikasi android

\subsection{Perancangan Sistem}

a. Gambaran Umum Sistem 


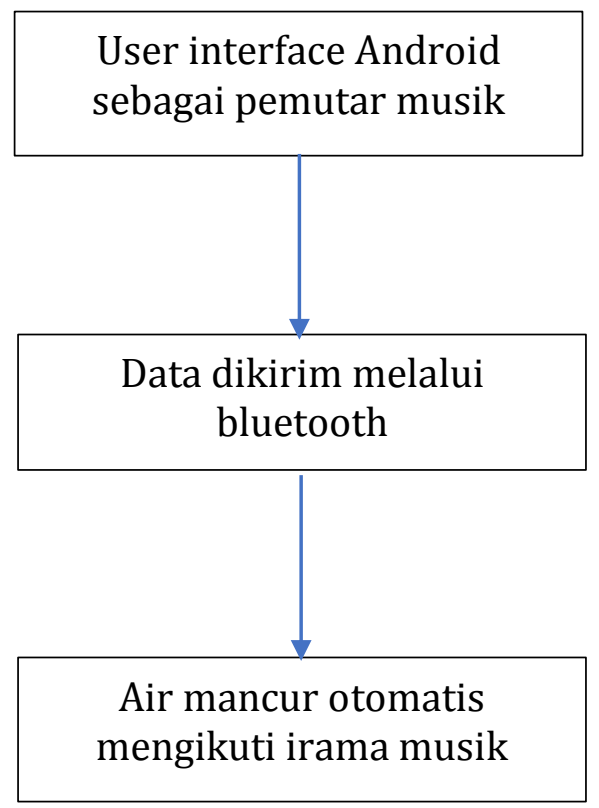

Gambar 2.7 gambaran umum sistem

Aplikasi pemutar musik pada smartphone android di koneksikan dengan modul bluetooth, dan memilih lagu yang di inginkan. Air mancur akan keluar sesuai dengan irama musik.

b. Perancangan perangkat keras

Perancangan perangkat keras terdiri dari modul bluetooth, df player, Transistor TIP $31 \mathrm{C}$ dan pompa air submersible.

1. Pada penelitian ini menggunakan media komunikasi bluetooh $\mathrm{HC}-05$ di sambungkan dengan modul arduino uno. Rangkaian pada modul terdapat pada gambar 2.6

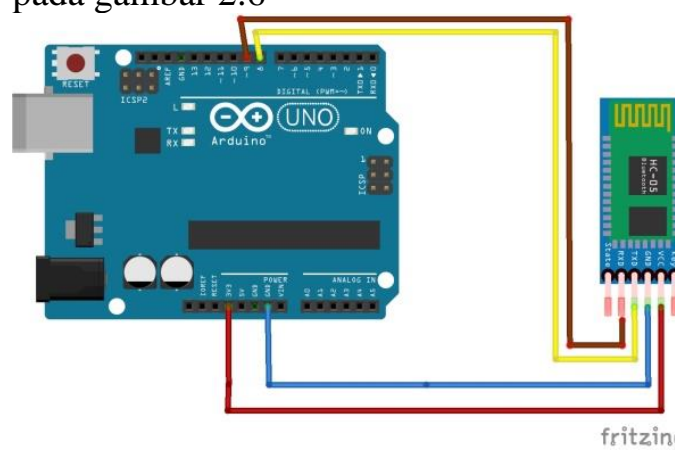

Gambar 2.6 rangkain modul HC-05 dan arduino

\begin{tabular}{|l|l|l|}
\hline Pin HC-05 & $\begin{array}{l}\text { Pin Arduino } \\
\text { Uno }\end{array}$ & Warna Kabel \\
\hline $3.3 \mathrm{v}$ & $3.3 \mathrm{v}$ & Merah \\
\hline Gnd & Gnd & Biru \\
\hline $\mathrm{Tx}$ & 8 & Kuning \\
\hline $\mathrm{Rx}$ & 9 & Coklat \\
\hline
\end{tabular}

Tabel 2.1 Jalur modul HC-05 dan arduino

2. Perancangan pemutar musik DF player dengan arduino. Rangkaian modul seperti pada gambar 2.7 .

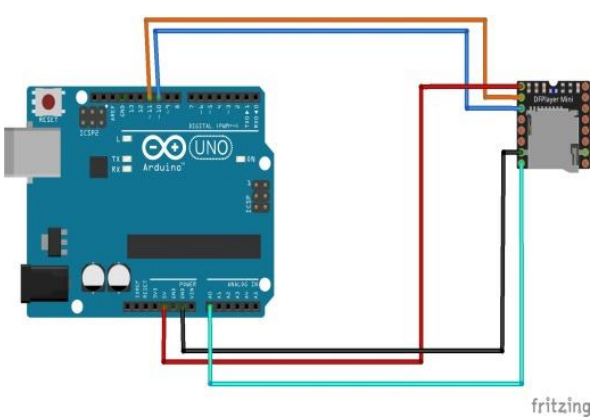

Gambar 2.8 Rangkaian modul Df layer dan Arduino

Tabel 2.2 Jalur DF player dan arduino

\begin{tabular}{|l|l|l|}
\hline $\begin{array}{l}\text { Pin Df } \\
\text { Player }\end{array}$ & $\begin{array}{l}\text { Pin Arduino } \\
\text { Uno }\end{array}$ & Warna Kabel \\
\hline $3.3 \mathrm{v}$ & $3.3 \mathrm{v}$ & Merah \\
\hline Gnd & Gnd & Biru \\
\hline Tx & 10 & Biru \\
\hline Rx & 11 & Orange \\
\hline Spk-2 & A0 & Cyan \\
\hline
\end{tabular}

1. Perancangan mesin pompa celup submersible dengan transistor dan arduino. Catu daya yang digunakan pompa air adalah power supply external dengan tegangan $5 \mathrm{v}$ dan arus $5 \mathrm{~A}$.

Rangkaian modul seperti pada gambar 2.9 


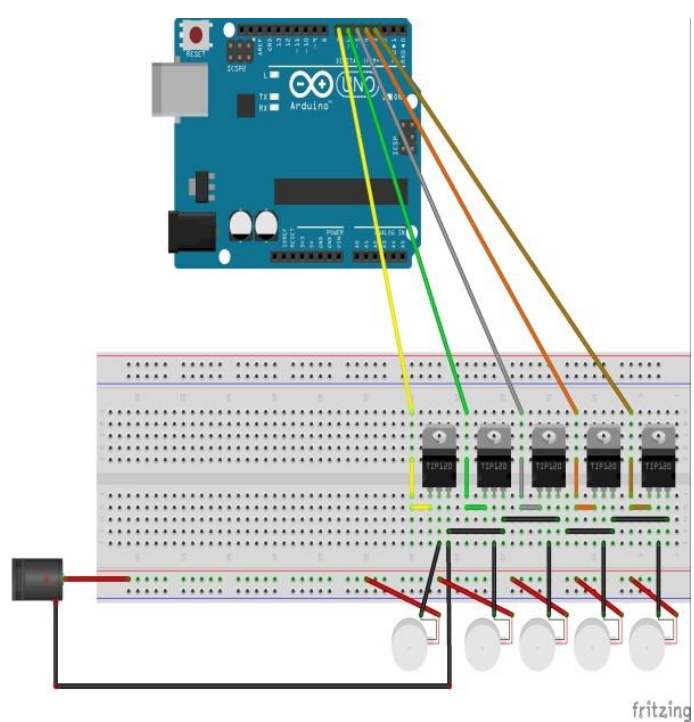

Gambar 2.9 Rancangan pompa air dan arduino

2. Rancangan kelesuruhan air mancur otomatis. Rangkaian modul seperti pada gambari 2.10

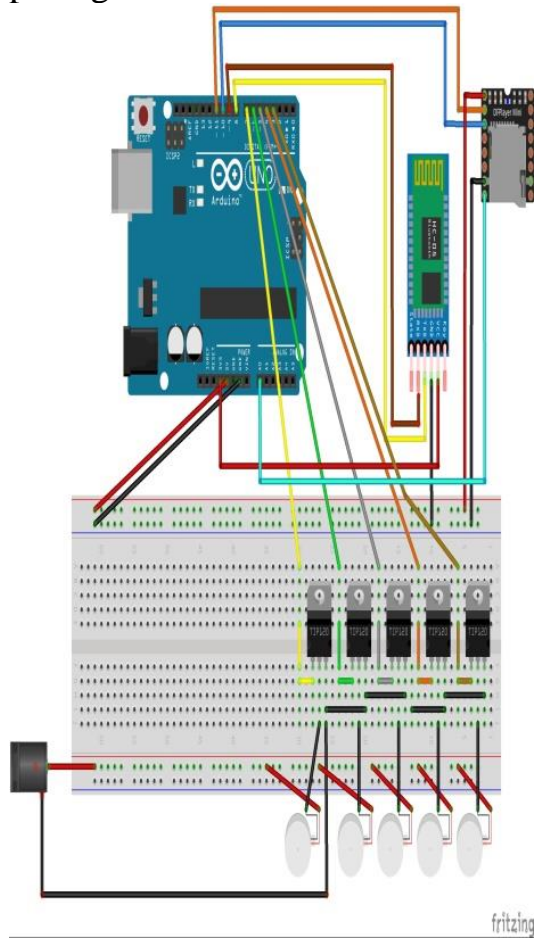

Gambar 2.9 Rancangan keseluruhan air mancur Otomatis

\section{HASIL DAN PEMBAHASAN}

Hasil penelitian diperoleh dari data pengujian dari tiap-tiap blok rangkaian dan rangkaian secara menyeluruh

\subsection{Komponen perangkat keras}

1. Pengujian modul bluetooth $\mathrm{HC}-05$ dengan aplikasi android

Kontrol musik pada air mancur ini adalah melalui bluetooth, ketika ingin memainkan air mancur, maka telebih dahulu harus menghubungkan aplikasi pemutar lagu dengan bluetooth yang terpasang pada arduino. Kemudian pada aplikasi android mencari bluetooth pada board arduino dan menghubungkan nya. Ketika aplikasi di jalankan untuk menghubungkan ke bluetooth maka melalui tombol disconnect untuk memunculkan daftar bluetooth yang aktif. Jika sudah terkoneksi air mancur dapat di kontrol melalui aplikasi android.

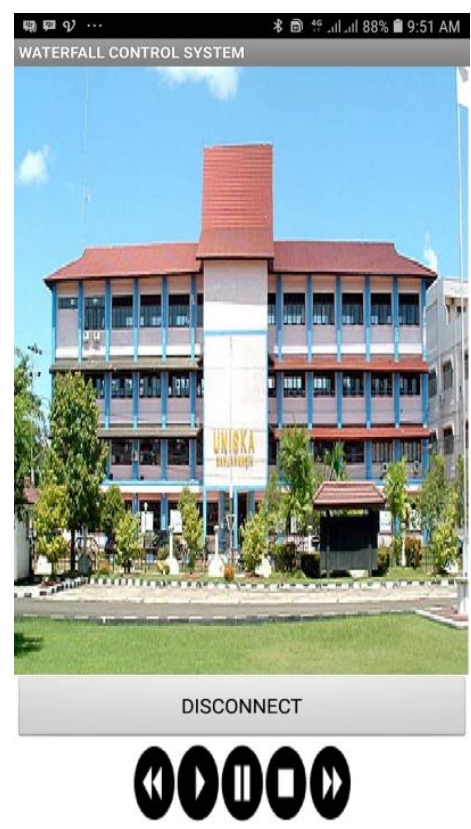

Gambar 3.0 tampilan aplikasi pengontrol air mancur 


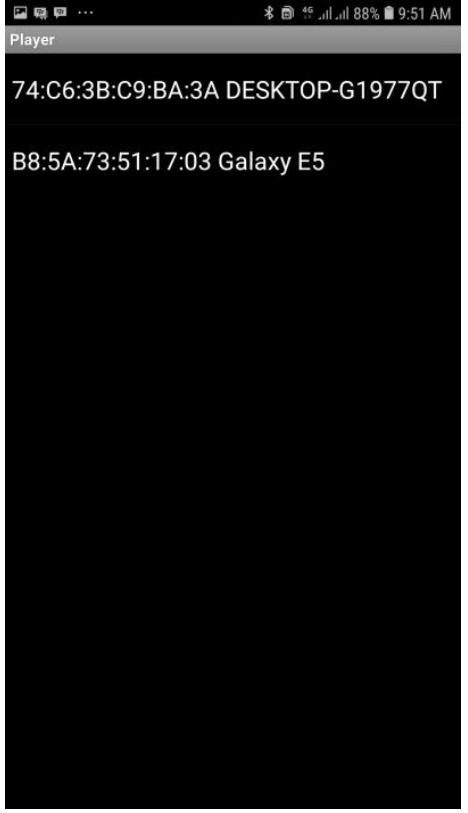

Gambar 3.1 Menghubungkan aplikasi android pada modul bluetooth $\mathrm{HC}-05$

2. Pengujian modul DF player

Modul ini berfungsi untuk meletakan file mp3 pada sd card, kemudian dengan aplikasi pemutar musik ini file mp3 akan diputar pada aplikasi android yang sudah terhubung dengan modul bluetooth hc-05.

3. Pengujian air mancur

Ketinggian air dan irama yang keluar dari pompa air tergantung dari lagu yang di putar. Pada air mancur ini pompa yang digunakan sebanyak 5 (lima) buah. Ketinggian air pada setiap pompa air tidak sama.

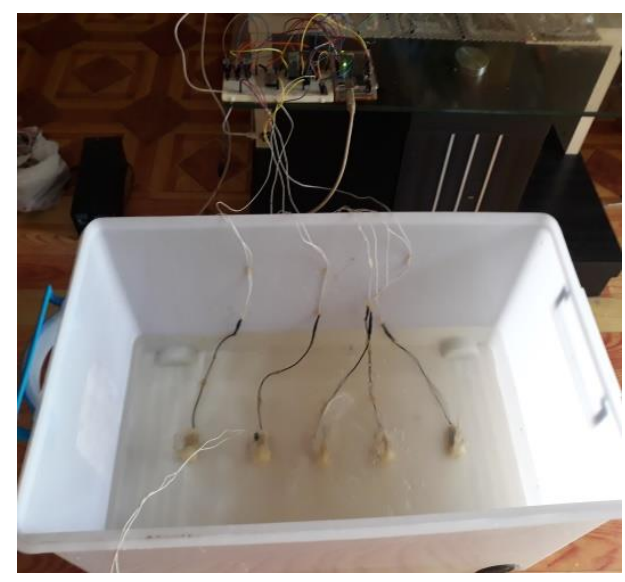

Gambar 3.2

\section{Aplikasi Android}

Air mancur otomatis di kontrol melalui aplikasi android, koneksi aplikasi dengan arduino melalui sebuah modul bluetooth. Data file mp3 diletakan di sd card pada modul df player yang terhubung dengan arduino. Setelah terhubung dengan bluetooh file mp3 akan muncul pada aplikasi dan ketika di putar maka air mancur akan aktif mengikuti irama musik.

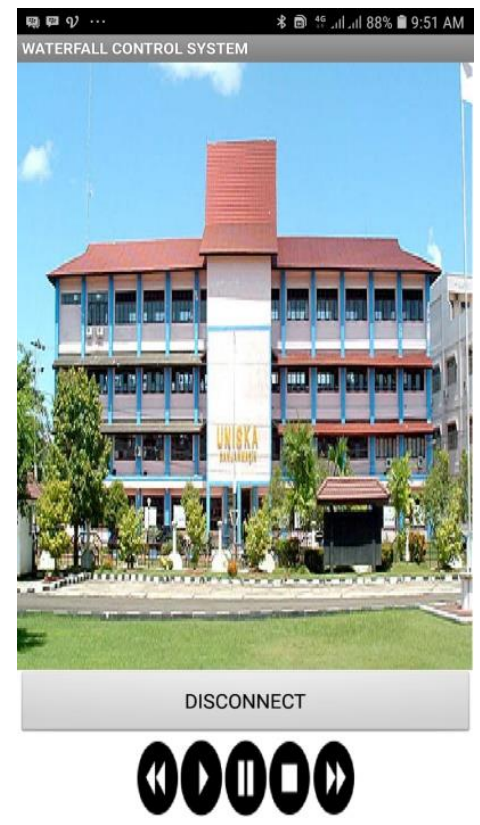

Gambar 3.3 pengujian dengan aplikasi pemutar musik

\section{SIMPULAN}

Dari tahap perancangan, pembuatan, dan hasil pengujian yang telah dilakukan, dapat diperoleh kesimpulan sebagai berikut:

a. Dengan variasi irama musik maka tegangan yang dihasilkan akan bervariasi, tegangan masukan kesistem dengan pengontrolan menggunakan arduino uno maka sistem mampu mengatur transistor TIP 31C sehingga pompa air dapat diatur dan irama musik dapat mengatur keluaran air yang bervariasi

b. Jenis lagu yang diputar akan menghasilkan tinggi rendahnya pancuran air yang berbeda. 


\section{DAFTAR PUSTAKA}

[1]. A. Zaenuri,U.Wibawa and E.Maulana., "Implementasi Bluetooth HC-05 untuk Memperbarui Informasi Pada Perangkat Running Text Berbasis Android", Jurnal EECCIS, Vol. 9, No.6, Dec 2015.

[2]. I.G.Nurhayata, "Pengembangan Prototipe Sistem Kontrol Mp3 Player Berbasis Radio Frequency Identification Pada Sistem Pelayanan Informasi Objek Museum, Jurnal Sains dan Teknologi, Vol.4, No.1, April 2015.

[3]. Robert, "Rancang Bangun Sistem Air Mancur Otomatis Berbasis Mikrokontroler AT89S", Untan, Vol.1, No.1, Maret 2013.

[4]. Motorolla, " Motorolla Semiconductor Technical Data", 1995.

[5]. Robot Wiki, "DFPlayer Mini SKU:DFR0299”, Agustus 2014. 